\title{
Fingolimod for multiple sclerosis and emerging indications: appropriate patient selection, safety precautions, and special considerations
}

This article was published in the following Dove Press journal:

Therapeutics and Clinical Risk Management

19 February 2016

Number of times this article has been viewed

\section{Ilya Ayzenberg \\ Robert Hoepner \\ Ingo Kleiter}

Department of Neurology, St Josef Hospital, Ruhr University Bochum, Bochum, Germany
Correspondence: Ingo Kleiter Department of Neurology, St Josef Hospital, Ruhr University Bochum, Gudrunstreet 56, 4479I Bochum,

Germany

Tel +492345092410

Fax +49 23450924 II

Email ingo.kleiter@rub.de
Abstract: Fingolimod (FTY720), an immunotherapeutic drug targeting the sphingosine-1phosphate receptor, is a widely used medication for relapsing-remitting multiple sclerosis (MS). Apart from the pivotal Phase III trials demonstrating efficacy against placebo and interferon$\beta$-1a once weekly, sufficient clinical data are now available to assess its real-world efficacy and safety profile. Approved indications of fingolimod differ between countries. This discrepancy, to some extent, reflects the intermediate position of fingolimod in the expanding lineup of MS medications. With individualization of therapy, appropriate patient selection gets more important. We discuss various scenarios for fingolimod use in relapsing-remitting MS and their pitfalls: as first-line therapy, as escalation therapy after failure of previous immunotherapies, and as de-escalation therapy following highly potent immunotherapies. Potential side effects such as bradycardia, infections, macular edema, teratogenicity, and progressive multifocal leukoencephalopathy as well as appropriate safety precautions are outlined. Disease reactivation has been described upon fingolimod cessation; therefore, patients should be closely monitored for MS activity for several months after stopping fingolimod. Finally, we discuss preclinical and clinical data indicating neuroprotective effects of fingolimod, which might open the way to future indications such as stroke, Alzheimer's disease, and other neurodegenerative disorders.

Keywords: immunotherapy, bradycardia, progressive multifocal leukoencephalopathy, neuroprotection, stroke, Alzheimer's disease

\section{Introduction}

Fingolimod (FTY720, [Gilenya ${ }^{\circledR}$, Novartis Pharmaceuticals, Basel, Swaizerland]) belongs to a class of molecules targeting the sphingolipid-regulated signaling system. ${ }^{1,2}$ Within the body, fingolimod is rapidly phosphorylated to fingolimod phosphate, the active formulation of the drug, which binds to four of the five known sphingosine-1phosphate (S1P) receptors. The main effects on immune cells are transmitted through the sphingosine1P1 receptor. After ligation, the sphingosine1P1 receptor is internalized and degraded, ${ }^{3}$ which leads to lymphocyte homing in peripheral lymphatic tissues and prevents the invasion of autoaggressive T-cells into the central nervous system (CNS) without suppression of systemic immune responses. ${ }^{4,5}$

Fingolimod was shown to be effective in experimental autoimmune encephalomyelitis, ${ }^{6}$ an animal model of multiple sclerosis (MS), and subsequently investigated in two Phase III clinical trials for relapsing-remitting (RR)MS. ${ }^{7}$ In these trials, fingolimod was demonstrated to be a safe and effective drug. The FTY720 Research Evaluating Effects of Daily Oral therapy in Multiple Sclerosis (FREEDOMS) trial was a double-blind, placebocontrolled study analyzing the annualized relapse rate (ARR; primary end point) and the 
time to disability progression (secondary end point) in 1,272 RRMS patients receiving fingolimod $(0.5$ or $1.25 \mathrm{mg} / \mathrm{d})$ or placebo. ${ }^{8}$ Both doses of fingolimod were demonstrated to reduce the ARR significantly and also decreased the risk of disability progression within the observation period of 24 months. A subgroup analysis revealed high efficacy of fingolimod in therapy-naïve patients and those pretreated with glatiramer acetate or interferon- $\beta .{ }^{9}$ Trial Assessing Injectable Interferon vs FTY720 Oral in RRMS (TRANSFORMS), a 12-month, double-dummy controlled study compared fingolimod $(0.5$ or $1.25 \mathrm{mg} / \mathrm{d})$ with interferon- $\beta$ - $1 \mathrm{a}$ im $(30 \mu \mathrm{g} / \mathrm{d})$ in 1,153 patients with RRMS. ${ }^{10}$ A significant $52 \%$ reduction of the ARR could be reproduced. However, in this study, no differences in disability progression were observed between groups, probably due to the shorter observation time. As two fatal infections occurred in the high-dose group, and no differences in efficacy were observed between both dosages, the $0.5 \mathrm{mg} / \mathrm{d}$ dose was further developed for clinical application. Common adverse events were herpes infections, bradycardia, atrioventricular block, macular edema, skin cancer, and elevated liver enzymes. ${ }^{8,10}$ Recently, the efficacy and safety profile of fingolimod was further evaluated by a long-term observational study investigating the FREEDOMS study population over a period of 60 months. ${ }^{11}$ In this extension study, 920 patients with RRMS were included, and ARR as well as brain volume loss measured by magnetic resonance imaging (MRI) were significantly lower in each treatment group compared with placebo, whereas adverse events were equally distributed within the treatment and the placebo groups. Also, FREEDOMS II, a placebo-controlled, double-blind, Phase III clinical trial of 1,083 patients with RRMS analyzing ARR after 24 months (primary outcome) and brain volume change as well as time to confirmed disability progression at 3 months (secondary outcome) partially confirmed the efficacy of fingolimod. ${ }^{12}$ In this study, a $48 \%$ reduction of the ARR (fingolimod $0.5 \mathrm{mg} / \mathrm{d}$ vs placebo) and a significantly lower brain volume loss were recorded, whereas significant effects on disability progression were not observed.

Fingolimod was the first oral drug for the treatment of RRMS and was shown to be highly effective in reducing the relapse rate. Since market launch in 2010, approximately 130,000 patients have received fingolimod; thus, in addition to the Phase II and III clinical trials, sufficient clinical data is now available to assess the real-world efficacy and safety profile of fingolimod.

\section{Appropriate patient selection}

Fingolimod is approved for the treatment of relapsing MS in many countries of the world; however, there is some difference in the indications. While fingolimod has been approved as a first-line therapy in the USA, Australia, and Switzerland without further restrictions, ${ }^{13-15}$ the regulatory agencies in the European Union and Canada were more cautious and have approved fingolimod as a second-line therapy for patients who failed to respond to baseline therapy or have a rapidly progressive disease course. ${ }^{16,17}$ In the USA and Australia, fingolimod can be also administered in secondary progressive MS with superimposed relapses. The discrepancy of approved indications, to some extent, reflects the intermediate position of fingolimod in the lineup of MS medications. As the number of MS therapies is likely to increase in the next few years, positioning of each medication will be even more complicated. It is important to note that the approval status, treatment guidelines, and the actual postmarketing use can differ from the investigated population in the pivotal clinical trials, making treatment decisions based on well-defined criteria difficult. Hence, one attempt is to tailor therapy to individual needs, taking into account the benefits, risks, and patient preferences obtained through shared decision processes. ${ }^{18}$ Once the decision to start fingolimod is made, an adequate observational program and structured patient education might help to enhance patient knowledge and self-efficacy and increase adherence to the therapy. ${ }^{19}$ In this section, we will outline the criteria for appropriate patient selection for fingolimod therapy.

\section{Fingolimod as first-line therapy for relapsing $M S$}

After a first demyelinating event, called clinically isolated syndrome, in the absence of MRI signs of dissemination in time disease activity is often difficult to assess. Many neurologists still use interferon- $\beta$ or glatiramer acetate as first-line therapies, because treatment and side effects are well known, and the latter are perceived as mild. However, where approved fingolimod can also be used as the initial therapy for relapsing MS when dissemination in time has been shown according to the current McDonald criteria. ${ }^{20}$ Because of its superior efficacy compared to interferon- $\beta,{ }^{10}$ this approach although not proven - might have the advantage of less patients experiencing a second clinical event or requiring escalation of therapy. Fingolimod as an initial therapy seems to be of particular interest in situations where already more than one clinical event has occurred or where other signs of an unfavorable disease course - eg, high lesion load/several active lesions on MRI, severe deficits during relapses, or incomplete remission from relapses - are present.

According to regulatory affairs, the European Medicines Agency recommended first-line fingolimod therapy only in 
case of $\geq 2$ relapses a year, progression of disability, and gadolinium-enhancing or new T2-lesions on MRI. ${ }^{16}$ In the USA and Switzerland, there are no special restrictions for administration of fingolimod in relapsing MS. ${ }^{13,14}$ Most objective and strong data from the Phase III clinical trials are based on patient cohorts with an $A R R \geq 1.0$. These patients have a high probability of a good clinical response to fingolimod, so the benefits of the therapy clearly outweigh adverse effects. Taking into account rare but life-threatening side effects, we suggest that fingolimod should not be a medication of first choice in a very mild course of disease or clinically isolated syndrome. Confirmed diagnosis of MS and ongoing, at least moderate, disease activity are recommended to justify treatment-related risks. In patients with mild disease activity who reject or do not tolerate other presumably safer therapies, fingolimod may be given after providing detailed information to the patients about potential adverse effects. The risk of rare paradoxical disease exacerbations should also be taken into account when starting fingolimod in such mild cases. ${ }^{21-25}$

\section{Fingolimod as escalation therapy for relapsing $M S$}

In Europe, fingolimod has mainly been used as an escalation therapy after baseline interferon- $\beta$ or glatiramer acetate therapy. Because of regulatory recommendations, the requirements for a switch to fingolimod therapy until recently were quite conservative and included insufficient effect of at least one other immunomodulatory therapy (of at least 1 year duration) and ongoing disease activity (defined as $\geq 1$ relapse in the last year and gadolinium-enhancing or $>9$ T2-lesions on MRI). However, modern principles of MS therapy aim to keep patients free from disease activity, and so even clinically silent events with ongoing MRI activity might demand more effective therapy. According to results of the TRANSFORMS study, fingolimod is substantially more effective than once-weekly interferon- $\beta-1 \mathrm{a} .{ }^{10}$ Also in those patients switched from other therapies (in $>80 \%$ from glatiramer acetate and interferon- $\beta$ ) to fingolimod by inclusion into FREEDOMS and FREEDOMS II studies, a significant reduction of both ARR (-48\%) and 3-month confirmed Expanded Disability Status Scale (EDSS) progression $(-34 \%)$ was demonstrated. ${ }^{26}$ To the best of our knowledge, there are no direct comparative studies with glatiramer acetate. However, according to a retrospective analysis, patients switched from interferon- $\beta$ (because of ongoing disease activity) to fingolimod had $62 \%$ less relapses compared to those switched to glatiramer acetate. ${ }^{27}$ More favorable outcomes after switching from injectable therapies to fingolimod compared with switching to another injectable therapy have been confirmed in a prospective study evaluating 1,053 patients with $\mathrm{RRMS}^{28}$ and in another retrospective multicenter study. ${ }^{29}$ Generally, the risk-benefit ratio of fingolimod seems to be close to that of dimethylfumarate, which can be another option for treating patients with relapsing MS with moderate disease activity. ${ }^{30,31} \mathrm{Dim}-$ ethylfumarate requires fewer preexaminations; however, it is associated with more frequent, unpleasant gastrointestinal and flush complaints at the start of therapy. ${ }^{32}$ In patients with a particularly aggressive disease course, a switch to natalizumab (preferably in John Cunningham virus (JCV)antibody negative cases), upcoming anti-CD20 monoclonal antibodies, or in some cases, alemtuzumab, rather than fingolimod should be considered. According to a large observational study, an escalation from injectable therapies to natalizumab was significantly more effective compared to fingolimod. ${ }^{33}$

\section{Fingolimod as de-escalation therapy for relapsing MS}

Several highly effective MS therapies (eg, natalizumab in JCV-antibody positive patients and mitoxantrone) can be administered for a limited period of time only. Unfortunately, high disease activity in these patients demands further active therapy, and fingolimod can be an option for the subsequent de-escalation. Several studies have evaluated the switch from natalizumab to fingolimod, which is a common clinical situation considering that natalizumab often has to be stopped for safety reasons. ${ }^{34}{ }^{42}$ Patients starting fingolimod within 6 months after the last natalizumab infusion had a significantly lower relapse rate compared to patients without any subsequent therapy or those treated with glatiramer acetate. ${ }^{35}$ Still, approximately $10 \%-30 \%$ of the patients on fingolimod experienced relapses, especially during the first 6 months after switch of therapy. ${ }^{34,39-42}$ The degree of disability, probably reflecting previous disease activity, can be used as a prognostic factor in these patients: the majority of patients with EDSS $<3.0$ at stopping natalizumab were relapse free on fingolimod therapy for at least 1 year. ${ }^{37}$ In most studies, a shorter washout period of 8 to a maximum of 12 weeks was clearly associated with less clinical and MRI disease activity. ${ }^{34,36,37,39,40,42}$ However, the recently published cases of the so-called "carry-over" progressive multifocal leukoencephalopathy (PML) in patients who started fingolimod 1-3 months after natalizumab cessation demonstrate a potential risk of a short washout period. ${ }^{43,44}$ In order to reduce the risk of "carry-over" PML, a control MRI at natalizumab cessation should be performed. However, as we described 
previously, an early monofocal manifestation of PML may be difficult to differentiate from a new MS lesion. ${ }^{45}$ Current data suggest, a 2- to 3-month washout period after natalizumab therapy. ${ }^{35,37,39,41,42}$ This time interval is also supported by pharmacodynamic data: 8 weeks after natalizumab cessation, the saturation of VLA-4 on lymphocyte membranes is still approximately $70 \%-80 \%$ and decreases after week 10 only. ${ }^{46}$ Because some patients experience relapses with a washout period of 2-3 months, an even shorter time to start of fingolimod might be advisable in those patients in whom PML has been ruled out.

Fingolimod might also be an option for de-escalation after other highly active medications, including anti-CD20 antibodies, alemtuzumab, or mitoxantrone (in case of its administration in patients with relapsing MS); however, further clinical observations are needed to evaluate the risks. Because of a possible overlap of immunosuppressive effects, the washout period must be sufficient to restore immune function. Serious infections, including PML, tumors, and cardiac pathology (in case of mitoxantrone), must be excluded before start of fingolimod. Unfortunately, up to now, there is a lack of data, concerning special risks of fingolimod after other therapies except natalizumab; these patients must be thoroughly monitored for side effects.

\section{Fingolimod for primary and secondary progressive MS?}

According to recently reported results of the Phase III FTY720 in Patients With Primary Progressive Multiple Sclerosis (INFORMS) study, fingolimod did not delay the time to sustained disability progression in primary progressive MS. ${ }^{47}$ No randomized trials for fingolimod in secondary progressive MS have been conducted yet. However, it might be worthwhile to look at older patients with relapsing MS (>40 years old), since underlying incipient progression might affect a significant proportion of these patients. Indeed, in an analysis describing this subgroup, fingolimod had no significant effect on relapse activity. ${ }^{48}$ Moreover, fingolimod was insufficient to prevent secondary progressive neurodegeneration in the animal model of experimental allergic encephalomyelitis. ${ }^{49}$ Taken together, there are no data supporting efficacy of fingolimod in primary or secondary progressive MS, and this therapy currently cannot be recommended in such patients.

\section{Special clinical situations}

When choosing a drug to treat MS, it is important to consider not only the degree of disease activity and frequency or extent of adverse effects, but also comorbidities, family planning, diagnostic uncertainties, and other factors. In the following situations, treatment with fingolimod should be avoided or only be applied after careful risk-benefit calculation:

1) Owing to safety reasons and often pronounced lymphopenia, fingolimod should only be used as a monotherapy. As far as we know, there are no studies or data on combination with other immunomodulatory or immunosuppressive therapies for MS. An exception is the treatment of relapses with high-dose corticosteroids or plasma exchange therapies, during which fingolimod treatment can be continued.

2) Fingolimod had teratogenic effects in preclinical studies and was associated with at least $7.6 \%$ of abnormal fetal development, including acrania and tetralogy of Fallot, in a relatively small cohort of 66 pregnancies. ${ }^{2,50}$ Fingolimod should not be given in women planning pregnancy, and an effective contraception must be recommended to all women of childbearing age during and at least 2 months after discontinuation of fingolimod. In case of a pregnancy with in utero exposure to fingolimod (defined as fingolimod therapy 6 weeks before conception or later), it is advisable to stop treatment immediately. Exposure to fingolimod is not an obligatory indication for pregnancy termination; however, patients must be informed about the potential risk of treatment-related developmental abnormalities and must be intensively screened. Fingolimod is included in the pregnancy category $\mathrm{C}$ of the US Food and Drug Administration (animal studies have shown an adverse effect on the fetus, there are no adequate and well-controlled studies in pregnant women, and the benefits of treatment in pregnant women may be acceptable despite its potential risks). Registration of pregnancies with in utero exposure to fingolimod in specialized registries (eg, https://www. gilenyapregnancyregistry.com) will allow estimating the risk more precisely in the future.

3) Fingolimod was shown to exacerbate disease in patients with neuromyelitis optica. ${ }^{51}$ Prior to start of fingolimod, the diagnosis of MS should be verified and, in any doubtful case, particularly with opticospinal manifestation, antibodies to aquaporin-4 should be tested.

4) Paradoxically, fingolimod may exacerbate the shortterm course of MS (10 days to 5 months) after the first administration. There is an increasing number of cases with newly evolving tumefactive lesions after start of fingolimod. ${ }^{21-25}$ Unfortunately, up to now no predictive features have been identified. A role of B-cells and of 
a transient leakage of the blood-brain barrier in disease pathogenesis in these patients have been discussed. ${ }^{22,24}$ There are no studies reporting fingolimod treatment in patients with prevalent tumefactive lesions; hence, special caution is needed in such cases, and fingolimod should probably be avoided.

\section{How should fingolimod therapy be monitored? Preceding safety measurements and first- dose assessment}

Before first-dose administration, pregnancy, liver dysfunction, and a pathological white blood cell count should be excluded (Table 1). ${ }^{16,52}$ Varicella zoster virus (VZV) immunity should be proofed by analyzing the VZV antibody titer, and negative cases should be vaccinated. In addition, an ophthalmologist should rule out a preexisting macular edema, and in patients who are at risk, a dermatologist should rule out a neoplasia of the skin. Since fingolimod had already demonstrated in the Phase III clinical trials to significantly reduce the heart rate and rarely cause atrioventricular block, a safety assessment is required for the first dose of fingolimod. Vital signs (blood pressure and heart rate) and an electrocardiogram (ECG) have to be obtained prior to fingolimod administration. If an atrioventricular block of grade 2 or higher (Mobitz type), a sick-sinus syndrome, or a QTc time $>470 \mathrm{~ms}$ (women) or $>450 \mathrm{~ms}$ (men) is present, fingolimod is contraindicated. Further contraindications include treatment with $\beta$-blockers, class-I or -III antiarrhythmics, or other medications causing bradycardia, chronic active infections (particularly hepatitis $\mathrm{B}$ and $\mathrm{C}$, tuberculosis, and human immunodeficiency virus), severe liver insufficiency, malignancies, and macular edema (particularly in patients with diabetes or uveitis).

After first-dose application, ECG and vital signs have to be recorded over a period of 6 hours. The observation can be stopped if the patient has a heart rate of $>80 \%$ of the baseline value, the last is not the lowest observed heart rate, and the patient is clinically asymptomatic. In any other case, the observation should be continued, preferably at a monitoring unit overnight. When the heart rate falls to $<40$ beats per minute or below $30 \%$ of the baseline value at any time during observation or if bradycardia is clinically symptomatic, fingolimod treatment should be stopped..$^{53}$

The frequency of cardiac events is being evaluated by the open, multicenter Study to vAlidate telemetRic ECG systems for firsT dose administration of Fingolimod (START) study. According to the recently presented interim results $(\mathrm{N}=3,951), 0.7 \%$ of patients had a bradycardia $<45$ beats per minute and $1.6 \%$ had an atrioventricular block of grade 2 or higher after the first-dose application of fingolimod. ${ }^{54}$

\section{Safety precautions during ongoing therapy}

Fingolimod treatment should be monitored at regular intervals (usually every 3 months) by a neurologist experienced in MS therapy. ${ }^{16,52}$ After start of fingolimod, liver enzymes and white blood cell count should be analyzed for the first time after 2 and 4 weeks and subsequently every 3 months (Table 1). If lymphocytes drop below 200/ $\mathrm{L}$, fingolimod should be stopped to prevent infectious diseases until lymphocytes increase to more than $600 / \mu \mathrm{L} .{ }^{52}$ Patients with low initial lymphocyte counts and women with low body

Table I Safety precautions

\begin{tabular}{|c|c|c|}
\hline Procedure & $\begin{array}{l}\text { Therapy-naïve patients or } \\
\text { pretreatment with interferon- } \beta \text {, } \\
\text { glatiramer acetate, dimethylfumarate }\end{array}$ & $\begin{array}{l}\text { Pretreatment with any } \\
\text { other immunotherapy }\end{array}$ \\
\hline Therapy-free interval before starting fingolimod & None & $\begin{array}{l}\text { Depending on previous } \\
\text { immunotherapy } \\
\mathrm{I}-12 \text { months }\end{array}$ \\
\hline $\begin{array}{l}\text { Laboratory examination (white blood cell } \\
\text { count, erythrocyte sedimentation rate, } \\
\text { transaminases, pregnancy test) }\end{array}$ & $\begin{array}{l}\text { Prior to start, after } 2 \text { and } 4 \text { weeks, and } \\
\text { every } 3 \text { months thereafter }{ }^{\mathrm{a}}\end{array}$ & \\
\hline Varicella zoster virus antibody titer & Prior to start & \\
\hline Blood pressure and heart rate & $\begin{array}{l}\text { Before and within the first } 6 \text { hours after } \\
\text { fingolimod initiation }\end{array}$ & \\
\hline Electrocardiogram & Before and 6 hours after fingolimod initiation & \\
\hline MRI scan of the brain & Prior to start & \\
\hline
\end{tabular}

Notes: Adapted from Kompetenznentz Multiple Sklerose. Praktische Aspekte der Therapie mit Fingolimod, [July 2015]. Munich, Germany, Pp. 18-19.52 aDoes not apply to ESR and pregnancy test.

Abbreviations: MRI, magnetic resonance imaging; ESR, erythrocyte sedimentation rate. 
mass index $\left(<18.5 \mathrm{mg} / \mathrm{m}^{2}\right)$ are at higher risk of developing lymphopenia. ${ }^{55}$ Liver enzymes $>5$-fold above the upper limit of normal at two different lab examinations should lead to withdrawal of fingolimod. ${ }^{16}$ In addition, yet described in a preliminary study, the dosage of fingolimod may be reduced from $0.5 \mathrm{mg}$ per day to $0.5 \mathrm{mg}$ every second or third day in patients with elevated liver enzymes or reduced lymphocyte counts. ${ }^{56}$ These reduction schemes led to a normalization of liver enzymes and lymphocyte counts in the reported eight patients (liver enzymes $>3$-fold of the upper limit of normal, $\mathrm{n}=2$; lymphocyte counts $\leq 200 / \mu \mathrm{L}, \mathrm{n}=6$ ). Despite freedom from clinical disease activity, MRI disease activity was found in five of eight patients after dose reduction. The off-label decision to reduce the dose of fingolimod appears to be a double-edged sword, and patients should be closely monitored with clinical visits and MRI scans within the following 6 months. Further, a checkup for macular edema should be performed in all patients after 3-4 months of therapy, which should be repeated annually in those with diabetes or known history of uveitis.

Although the rate of infections seems to be unrelated to lymphocyte counts and was not significantly elevated with fingolimod in randomized and observational trials, ${ }^{5,57}$ monitoring and rapid treatment of infections is advisable. Two cases of fatal hemophagocytic syndrome have occurred, both associated with infections. ${ }^{58}$ Furthermore, several cases of PML related to fingolimod treatment have been reported. Some of these cases probably were due to a "carry-over" effect, as patients received natalizumab prior to fingolimod. ${ }^{43,44}$ Nevertheless, until August 2015, two cases of PML occurred in patients treated exclusively with fingolimod. ${ }^{59}$ In both patients, no other predisposing factor, particularly no previous immunosuppression, was reported. The first case was a 49-year-old MS patient in whom PML occurred after 51 months of fingolimod therapy, with lymphopenia grade 3 in the last month before PML diagnosis. ${ }^{60}$ In the second case of a 54-year-old MS patient, fingolimod was taken for 2.5 years before the development of PML. The patient also had ulcerative colitis and was concomitantly treated with mesalazine. During fingolimod treatment, lymphopenia grades $2-3$ occurred. ${ }^{59}$ The frequency of PML in fingolimod currently is too low to allow for risk stratification, but a potential link between lymphopenia and PML has to be kept in mind. In comparison to natalizumab, the PML risk during fingolimod therapy seems to be comparatively low. Nevertheless, as PML is a severe neuroinfection occurring with various MS immunotherapies, ${ }^{61,62}$ and cases of posterior reversible encephalopathy syndrome (PRES) have been described, we suggest that patients with new cerebral symptoms during fingolimod treatment be investigated by MRI and, if suspicious, also JCV polymerase chain reaction from cerebrospinal fluid (CSF) be performed to definitely exclude any etiology other than MS disease activity.

\section{Special considerations How long should a patient be treated with fingolimod?}

In most patients with adequate indication, fingolimod is well tolerated and efficient enough to suppress disease activity and thus can be given for years. Randomized clinical studies and postmarketing experience overlook a duration of up to 7 years now. Apart from the known side effects, no new safety signals have been reported with long-term treatment yet. ${ }^{63,64}$ Reasons to discontinue fingolimod include breakthrough disease, family planning in women, or side effects (such as macular edema, serious infections, or lymphopenia). Patients are particularly vulnerable after cessation of fingolimod, and should be closely monitored for disease activity for several months. Taking into account a drug elimination half-time of 8 days, the normalization of peripheral lymphocytes takes 2-4 weeks. ${ }^{65}$ In agreement with this, several case reports described an increase of disease activity approximately $2-4$ months after stopping fingolimod. ${ }^{66-72}$ These patients developed tumefactive lesions or multiple disseminated gadoliniumenhanced lesions, in several cases with incomplete remission despite plasma exchange therapy. It is unclear whether this disease activity represents a specific rebound effect after fingolimod discontinuation or just restoration of a previously high disease activity. ${ }^{71}$ Under fingolimod, central memory T-cells, CC-chemokine receptor-7-positive naïve T-cells, and T-cells producing interleukin-17 (IL-17) are predominantly retained in lymph nodes. ${ }^{73}$ An overexpression of S1P1 receptors in entrapped lymphocytes and massive egress of the lymphocytes after fingolimod cessation described in animal models seem to be plausible explanations for such an aggressive disease reactivation in some patients. ${ }^{74}$ In case of fingolimod discontinuation, another MS therapy should be started as soon as possible, preferably after normalization of lymphocytes counts. It has not been identified yet which measures best prevent postcessation disease activity, but similar techniques as described after withdrawal of natalizumab might be applied. ${ }^{75}$

\section{Fingolimod and disability progression in $M S$}

The pivotal clinical trials ${ }^{8,10,12}$ showed conflicting results concerning disability progression under fingolimod. Although the FREEDOMS study revealed a 30\% reduction 
in the risk of disability progression, there was no significant effect in the FREEDOMS II trial., 812 Despite a similar study design, differences in the baseline patient characteristics (particularly a higher number of patients with baseline EDSS of 0, who actively progressed in all studied groups in FREEDOMS II) can explain these findings. In the post hoc analysis of patients with a baseline EDSS $>0$, a significant $30 \%$ reduction of disability progression has been confirmed. ${ }^{12}$ The TRANSFORMS study with only a 12-month duration and interferon- $\beta$-1a as an active comparator also revealed no significant effect on disability progression. ${ }^{10}$ However, the rate of brain volume loss, which is correlated with disability progression in $\mathrm{MS},{ }^{76}$ was significantly decreased under fingolimod treatment in all three Phase III studies. ${ }^{8,10,12}$ This effect was observed already 6 months after the start of fingolimod and was independent of the presence of contrastenhancing lesions. ${ }^{77,78}$ According to a recent analysis, reduction of the relapse rate and slowing of the brain volume loss under fingolimod therapy have an independent favorable effect on disability progression. ${ }^{79}$ Further evidence comes from registry studies. In patients with relapsing MS, fingolimod reduced the risk of disability progression compared to interferon- $\beta$ and glatiramer acetate by approximately $50 \%$ after switch from injectable therapies ${ }^{29}$ or de-escalation from natalizumab. ${ }^{40}$ Finally, in primary progressive MS, fingolimod had no significant effect on disease progression. ${ }^{47}$ It is unknown if the neurodegenerative mechanisms are similar in relapsing and progressive MS.

\section{Neuroprotective effects of fingolimod}

The CNS effects of fingolimod are supposed to be at least partly independent from lymphocyte sequestration, the main immunosuppressive effect of fingolimod. ${ }^{4}$ Being lipophilic, fingolimod can cross the blood-brain barrier and reach biologically active concentrations in the CNS even after oral administration. ${ }^{80} \mathrm{~S} 1 \mathrm{P}$ receptors are abundant in the $\mathrm{CNS}$ and are expressed by microglia (S1P1, S1P2, S1P3, and S1P5), astrocytes (S1P1, S1P2, and S1P3), oligodendrocytes (S1P1, S1P3, and S1P5), neurons (S1P1 and S1P3), and neural progenitor cells (S1P1, S1P2, S1P3, and S1P5). ${ }^{81}$ Particularly, its putative effects on oligodendrocytes raised the interest of fingolimod being a molecule with neuroprotective and remyelinating properties.

Fingolimod enhances proliferation of neural progenitor cells and protects hippocampal neural progenitor cells against radiation in vitro. ${ }^{82,83}$ In vitro experiments also revealed protective effects of fingolimod against $N$-methyl D-aspartate toxicity. ${ }^{84,85}$ In animal models of Rett syndrome and Alzheimer's disease (AD), fingolimod demonstrated neuroprotective properties, increasing expression of brainderived neurotrophic factor and ameliorating clinical features of disease. ${ }^{86-88}$ In oligodendrocyte progenitor cells and oligodendrocytes, fingolimod prevents serum- and glucose-deprivation-induced apoptosis. ${ }^{89,90}$ Based on these observations, remyelination during fingolimod has been investigated in various experimental models. Fingolimod enhanced remyelination in organotypic slice cultures; ${ }^{91}$ however, it was not effective in several preclinical studies in the rodent cuprizone model of demyelination. ${ }^{92-94}$ Despite the failure of fingolimod to increase remyelination in these models, it ameliorated axonal degeneration in both acute and chronically demyelinated lesions. ${ }^{94}$ A small retrospective study recently has shown that fingolimod treatment may also reduce the conversion rate from acute to chronic $\mathrm{T} 1$ hypointense lesions in MS patients. ${ }^{95}$

Experimental data indicating reduction of inflammatory activity of microglia under fingolimod are more consistent. Noda et $\mathrm{al}^{96}$ showed that fingolimod downregulates the production of proinflammatory cytokines tumor necrosis factor- $\alpha$, interleukin (IL)-1 $\beta$, and IL-6 by activated microglia in vitro and, in contrast, enhanced the synthesis of brain-derived neurotrophic factor and glial cell-derived neurotrophic factor. Fingolimod is also supposed to reduce astrocyte nitric oxide production and secondary neurodegeneration. Parallel upregulation of IL-1-receptor, IL-17A-receptor, and S1P1 and S1P3 in astrocytes was observed within MS lesions. ${ }^{97-99}$ Inhibiting both immunomodulatory (through IL-1 and IL-17) and nonimmune pathways (through S1P), fingolimod is believed to reduce astrocyte-mediated neurodegeneration. ${ }^{99}$ Interestingly, effects of fingolimod on experimental autoimmune encephalomyelitis are lost in mutant mice lacking S1P1 on astrocytes. ${ }^{100}$

Therefore, preclinical studies clearly demonstrate direct effects of fingolimod on CNS-resident cells. Whether these effects are relevant for the clinical use of fingolimod must be clarified in carefully designed clinical trials.

\section{Fingolimod for other indications}

Up to now, relapsing MS is the only approved indication for fingolimod, despite fingolimod having been tested in a number of other diseases in which autoimmune mechanisms play a substantial role or in which potential neuroprotective properties of fingolimod could be favorable (Figure 1). Clinical trials evaluating the efficacy of fingolimod in stroke, chronic inflammatory demyelinating polyneuropathy, and Rett syndrome are ongoing. ${ }^{101}$ 


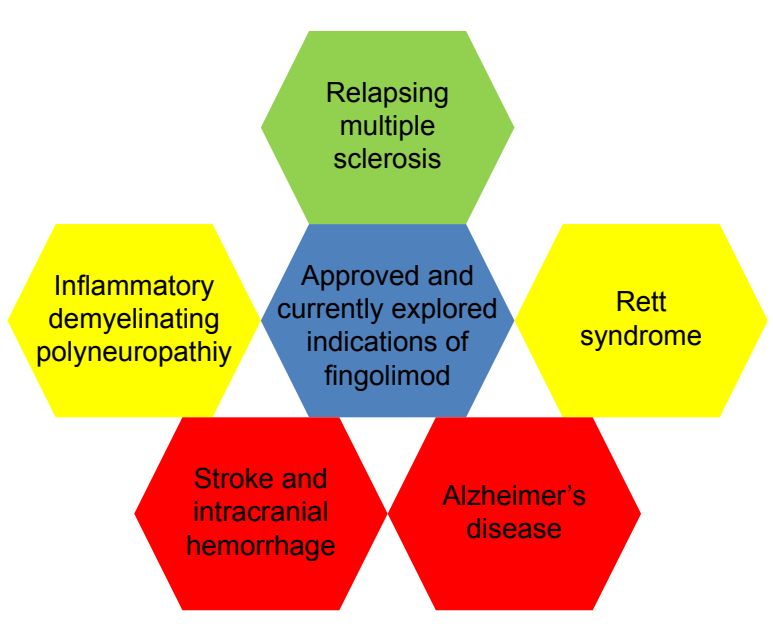

Figure I Current and potential future indications of fingolimod.

Notes: Red: results of small proof-of-concept studies or first laboratory evidence are available; yellow: first clinical trials are recruiting; green: actually labeled indication of fingolimod.

\section{Stroke}

Several mechanisms such as reperfusion, secondary inflammation, and edema enlarge stroke lesions up to $10 \%$ and often cause an increase of neurological deficits. ${ }^{102}$ Early disruption of the blood-brain barrier and lymphocyte infiltration play key roles in this process. ${ }^{103-105}$ In case of thrombolysis, inflammatory responses have also been supposed to increase hemorrhagic transformation of the ischemic lesion. ${ }^{106-108}$ Based on this hypothesis, Zhu et al ${ }^{109}$ reported a pilot trial (multicenter, open study, $\mathrm{N}=25$ ) of coadministration of fingolimod and alteplase in patients with stroke in the anterior circulation. Significantly lower lesion volume, less hemorrhagic transformation, and better long-term clinical recovery (90 days poststroke) were observed. Interestingly, the most substantial effects on lesion size occurred in fingolimodtreated patients between days 1 and 7 , a typical period of vasogenic edema and lesion enlargement due to postischemic inflammatory responses. ${ }^{104,110}$ Similar effects have been demonstrated in nonthrombolyzed patients with stroke. ${ }^{11}$ Moreover, in patients with intracranial hemorrhage (2-arm evaluator-blinded study, $\mathrm{N}=23$ ), early administration of fingolimod resulted in reduction of edema and improvement of clinical outcome. ${ }^{112}$ It is unknown how fingolimod exerts its effects in stroke. Reduction of intralesional lymphocytic infiltration, amelioration of blood-brain barrier disruption, and reperfusion injury, as well as putative direct neuroprotective effects are the supposed mechanisms of action in stroke. ${ }^{84-86,113}$ These small proof-of-concept studies must be interpreted with caution, and further large trials are needed to confirm these findings. Since patients with stroke are older than the typical MS patient and often receive multiple drugs, they are probably prone to more adverse effects, particularly bradycardia, atrioventricular block, and infections in the early poststroke period.

\section{$A D$ and other neurodegenerative disorders}

$\mathrm{AD}$ is a primary degenerative CNS disease in which both immunomodulatory and nonimmune effects of fingolimod are supposed to be favorable. Activation of microglia and astrocytes with secretion of proinflammatory cytokines have been described around the amyloid plaques. ${ }^{114}$ Ceramides and sphingomyelins correlate with concentration of tau and amyloid- $\beta(A \beta)$ in the cerebrospinal fluid and have been identified as potential biomarkers of $\mathrm{AD} .{ }^{115}$ Upregulation of proapoptotic ceramides was demonstrated in $\mathrm{AD} .{ }^{116-118}$ Sphingolipids are able to facilitate production of $A \beta$ peptide and $A \beta$-mediated neurotoxicity. ${ }^{119}$ In cell culture, fingolimod decreases production of all $A \beta$ protein species, inhibits $A \beta 42$ induced monocyte migration, and results in upregulation of brain-derived neurotrophic factor in a dose-dependent manner, preventing neurodegeneration induced by oligomeric $A \beta$ protein. ${ }^{87,120,121}$ In animal models of AD, fingolimod decreased $A \beta 40$ and increased $A \beta 42$ concentration, reduced caspase- 3 activation, and decreased neuronal damage, resulting in amelioration of the cognitive impairment. ${ }^{88,121,122}$

In addition to $\mathrm{AD}$, beneficial effects of fingolimod which were probably brain-derived neurotrophic factor-dependent, have been observed in mouse models of Huntigton's disease and Rett syndrome. ${ }^{86,123,124}$ A first clinical trial in Rett syndrome is currently recruiting patients. ${ }^{101}$ Further clinical studies are needed to clarify the clinical perspectives of agents modulating S1P signaling in neurodegenerative diseases.

\section{Inflammatory demyelinating polyneuropathies}

Fingolimod has also been shown to effectively suppress experimental autoimmune neuritis (EAN) in rats. ${ }^{125}$ The treatment was effective when given both before and after clinical manifestation of EAN. This effect of fingolimod is probably associated with suppression of IL-17-producing T-cells. ${ }^{126}$ Based on these preclinical data, one clinical trial is now recruiting patients with chronic inflammatory demyelinating polyneuropathy. ${ }^{101}$

\section{Conclusion and outlook}

Fingolimod, the first oral drug approved for relapsing MS, can be used in a wide spectrum of patients with MS. The most appropriate phase of relapsing MS for fingolimod treatment seems to be moderately active disease in young patients, but fingolimod also can be beneficial in cases of low active disease, particularly with intolerability to baseline therapies. Other important indications are escalation 
therapy after failure of baseline therapies and de-escalation treatment in patients stopping highly active immunotherapies. In the latter, predictive markers for breakthrough disease such as the EDSS or other biomarkers should be useful. ${ }^{37}$

As with every immunotherapy, benefits of fingolimod have to be weighed against risks, which are diverse owing to the nonspecific targeting of several S1P receptors in multiple tissues. Hence, further development of more specific S1P receptor modulators highly selective for S1P1 is awaited. Examples include siponimod (BAF312), ceralifimod (ONO4641), ponesimod (ACT128800), and ozanimod (RPC-1063), all of which have been validated in various animal models and are currently being tested in clinical trials for safety and efficacy, particularly in patients with MS, ulcerative colitis, and psoriasis. ${ }^{127,128}$

The identification of neuroprotective effects of fingolimod in cell culture and preclinical models opens interesting perspectives for treatment of the neurodegenerative process in MS, but unfortunately, clinical data have not yet conclusively shown a consistent effect on disease progression or other clinically relevant outcome parameters of neurodegeneration. However, if confirmed in humans, these findings might also pave the way for future indications of fingolimod such as stroke, $\mathrm{AD}$, and other neurodegenerative disorders.

\section{Acknowledgment}

The authors thank Orhan Aktas for the thoughtful comments on the manuscript.

\section{Disclosure}

Dr Ayzenberg has received travel reimbursement and consulting honoraria from Biogen-Idec and Roche Pharma. Dr Hoepner has received research and travel grants from Novartis and Biogen-Idec. Dr Kleiter has received travel reimbursements and speaker and consulting honoraria from Bayer Healthcare, Biogen-Idec, Novartis, and Chugai as well as research support from Bayer Healthcare, Biogen-Idec, Chugai, Diamed, and Novartis. The authors report no other conflicts of interest in this work.

\section{References}

1. Brinkmann V, Davis MD, Heise CE, et al. The immune modulator FTY720 targets sphingosine 1-phosphate receptors. J Biol Chem. 2002; 277(24):21453-21457.

2. Brinkmann V, Billich A, Baumruker T, et al. Fingolimod (FTY720): discovery and development of an oral drug to treat multiple sclerosis. Nat Rev Drug Discov. 2010;9(11):883-897.

3. Pham TH, Okada T, Matloubian M, Lo CG, Cyster JG. S1P1 receptor signaling overrides retention mediated by $\mathrm{G} \alpha$ i-coupled receptors to promote T cell egress. Immunity. 2008;28(1):122-133.
4. Chiba K, Yanagawa Y, Masubuchi Y, et al. FTY720, a novel immunosuppressant, induces sequestration of circulating mature lymphocytes by acceleration of lymphocyte homing in rats. I. FTY720 selectively decreases the number of circulating mature lymphocytes by acceleration of lymphocyte homing. J Immunol. 1998;160(10):5037-5044.

5. Yanagawa Y, Sugahara K, Kataoka H, Kawaguchi T, Masubuchi Y, Chiba K. FTY720, a novel immunosuppressant, induces sequestration of circulating mature lymphocytes by acceleration of lymphocyte homing in rats. II. FTY720 prolongs skin allograft survival by decreasing T cell infiltration into grafts but not cytokine production in vivo. J Immunol. 1998; 160(11):5493-5499.

6. Fujino M, Funeshima N, Kitazawa Y, et al. Amelioration of experimental autoimmune encephalomyelitis in Lewis rats by FTY720 treatment. J Pharmacol Exp Ther. 2003;305(1):70-77.

7. Aktas $\mathrm{O}, \mathrm{Küry} \mathrm{P}$, Kieseier B, Hartung HP. Fingolimod is a potential novel therapy for multiple sclerosis. Nat Rev Neurol. 2010;6(7):373-382.

8. Kappos L, Radue EW, O'Connor P, et al. A placebo-controlled trial of oral fingolimod in relapsing multiple sclerosis. $N$ Engl J Med. 2010; 362(5):387-401.

9. Kremenchutzky M, O’Connor P, Hohlfeld R, et al. Impact of prior treatment status and reasons for discontinuation on the efficacy and safety of fingolimod: subgroup analyses of the Fingolimod Research Evaluating Effects of Daily Oral Therapy in Multiple Sclerosis (FREEDOMS) study. Mult Scler Relat Disord. 2014;3(3):341-349.

10. Cohen JA, Barkhof F, Comi G, et al. Oral fingolimod or intramuscular interferon for relapsing multiple sclerosis. N Engl J Med. 2010; 362(5):402-415.

11. Kappos L, O'Connor P, Radue EW, et al. Long-term effects of fingolimod in multiple sclerosis: the randomized FREEDOMS extension trial. Neurology. 2015;84(15):1582-1591.

12. Calabresi PA, Radue EW, Goodin D, et al. Safety and efficacy of fingolimod in patients with relapsing-remitting multiple sclerosis (FREEDOMS II): a double-blind, randomised, placebo-controlled, phase 3 trial. Lancet Neurol. 2014;13(6):545-556.

13. Gilenya [prescribing information]. US Food and Drug Administration. Basel, Switzerland: Novartis International AG. Available from:http://www. accessdata.fda.gov/drugsatfda_docs/label/2015/022527s016lbl.pdf. Accessed October 24, 2015.

14. Gilenya [Azneimittelinformation]. Swiss Agency for Therapeutic Products. Bern, Switzerland: Swissmedic. Available from: www. swissmedicinfo.ch. Accessed October 24, 2015. German.

15. Administration AGD of HTG. Australian Public Assessment Report for prescription medicines: fingolimod. Australian Government, Department of Health Goods Administration. Available from: https://www. tga.gov.au/artg/artg-id-169890. Accessed November 30, 2015.

16. Gilenya [Summary of product characteristics]. London, UK: European Medicines Agency. Available from: http://www.ema.europa.eu/ docs/en_GB/document_library/EPAR_-_Product_Information/ human/002202/WC500104528.pdf. Accessed October 24, 2015.

17. Gilenya product monograph. Health Canada. Available from: http:// webprod5.hc-sc.gc.ca/dpd-bdpp/dispatch-repartition.do?lang=eng. Accessed October 24, 2015.

18. Köpke S, Kern S, Ziemssen T, et al. Evidence-based patient information programme in early multiple sclerosis: a randomised controlled trial. J Neurol Neurosurg Psychiatry. 2014;85(4):411-418.

19. Zimmer A, Bläuer C, Coslovsky M, Kappos L, Derfuss T. Optimizing treatment initiation: effects of a patient education program about fingolimod treatment on knowledge, self-efficacy and patient satisfaction. Mult Scler Relat Disord. 2015;4(5):444-450.

20. Polman CH, Reingold SC, Banwell B, et al. Diagnostic criteria for multiple sclerosis: 2010 revisions to the McDonald criteria. Ann Neurol. 2011;69(2):292-302.

21. Visser F, Wattjes MP, Pouwels PJ, Linssen WH, van Oosten BW. Tumefactive multiple sclerosis lesions under fingolimod treatment. Neurology. 2012;79(19):2000-2003.

22. Pilz G, Harrer A, Wipfler P, et al. Tumefactive MS lesions under fingolimod: a case report and literature review. Neurology. 2013;81(19): 1654-1658. 
23. Hellmann MA, Lev N, Lotan I, et al. Tumefactive demyelination and a malignant course in an MS patient during and following fingolimod therapy. J Neurol Sci. 2014;344(1-2):193-197.

24. Harirchian MH, Taalimi A, Siroos B. Emerging tumefactive MS after switching therapy from interferon- $\beta$ to fingolimod: a case report. Mult Scler Relat Disord. 2015;4(5):400-402.

25. Boangher S, Goffette S, Van Pesch V, Mespouille P. Early relapse with tumefactive MS lesion upon initiation of fingolimod therapy. Acta Neurol Belg. Epub June 14, 2015.

26. Derfuss T, Bergvall NK, Sfikas N, Tomic DL. Efficacy of fingolimod in patients with highly active relapsing-remitting multiple sclerosis. Curr Med Res Opin. 2015;31(9):1687-1691.

27. Bergvall N, Makin C, Lahoz R, et al. Relapse rates in patients with multiple sclerosis switching from interferon to fingolimod or glatiramer acetate: a US claims database study. PLoS One. 2014;9(2): e88472.

28. Fox E, Edwards K, Burch G, et al. Outcomes of switching directly to oral fingolimod from injectable therapies: results of the randomized, openlabel, multicenter, Evaluate Patient OutComes (EPOC) study in relapsing multiple sclerosis. Mult Scler Relat Disord. 2014;3(5):607-619.

29. He A, Spelman T, Jokubaitis V, et al. Comparison of switch to fingolimod or interferon $\beta /$ glatiramer acetate in active multiple sclerosis. JAMA Neurol. 2015;72(4):405-413.

30. Gold R, Kappos L, Arnold DL, et al. Placebo-controlled phase 3 study of oral BG-12 for relapsing multiple sclerosis. N Engl J Med. 2012; 367(12):1098-1107.

31. Fox RJ, Miller DH, Phillips JT, et al. Placebo-controlled phase 3 study of oral BG-12 or glatiramer in multiple sclerosis. N Engl J Med. 2012; 367(12):1087-1097.

32. Phillips JT, Hutchinson M, Fox R, Gold R, Havrdova E. Managing flushing and gastrointestinal events associated with delayed-release dimethyl fumarate: experiences of an international panel. Mult Scler Relat Disord. 2014;3(4):513-519.

33. Kalincik T, Horakova D, Spelman T, et al. Switch to natalizumab versus fingolimod in active relapsing-remitting multiple sclerosis. Ann Neurol. 2015;77(3):425-435.

34. Rinaldi F, Seppi D, Calabrese M, Perini P, Gallo P. Switching therapy from natalizumab to fingolimod in relapsing-remitting multiple sclerosis: clinical and magnetic resonance imaging findings. Mult Scler. 2012;18(11):1640-1643.

35. Laroni A, Brogi D, Milesi V, Abate L, Uccelli A, Mancardi G. Early switch to fingolimod may decrease the risk of disease recurrence after natalizumab interruption. Mult Scler. 2013;19(9):1236-1237.

36. Havla J, Tackenberg B, Hellwig K, et al. Fingolimod reduces recurrence of disease activity after natalizumab withdrawal in multiple sclerosis. J Neurol. 2013;260(5):1382-1387.

37. Hoepner R, Havla J, Eienbröker C, et al. Predictors for multiple sclerosis relapses after switching from natalizumab to fingolimod. Mult Scler. 2014;20(13):1714-1720.

38. Bianco A, Patanella AK, Nociti V, et al. Second-line therapy with fingolimod for relapsing-remitting multiple sclerosis in clinical practice: the effect of previous exposure to natalizumab. Eur Neurol. 2015; 73(1-2):57-65.

39. Kappos L, Radue EW, Comi G, et al. Switching from natalizumab to fingolimod: a randomized, placebo-controlled study in RRMS. Neurology. 2015;85(1):29-39.

40. Iaffaldano P, Lucisano G, Pozzilli C, et al. Fingolimod versus interferon $\beta /$ glatiramer acetate after natalizumab suspension in multiple sclerosis. Brain J Neurol. 2015;138(Pt 11):3275-3286.

41. Jokubaitis VG, Li V, Kalincik T, et al. Fingolimod after natalizumab and the risk of short-term relapse. Neurology. 2014;82(14):1204-1211.

42. Cohen M, Maillart E, Tourbah A, et al. Switching from natalizumab to fingolimod in multiple sclerosis: a French prospective study. JAMA Neurol. 2014;71(4):436-441.

43. Killestein J, Vennegoor A, van Golde AE, Bourez RL, Wijlens ML, Wattjes MP. PML-IRIS during fingolimod diagnosed after natalizumab discontinuation. Case Rep Neurol Med. 2014;2014:307872.
44. Calic Z, Cappelen-Smith C, Hodgkinson SJ, McDougall A, Cuganesan R, Brew BJ. Treatment of progressivemultifocal leukoencephalopathy-immune reconstitution inflammatory syndrome with intravenous immunoglobulin in a patient with multiple sclerosis treated with fingolimod after discontinuation of natalizumab. J Clin Neurosci. 2015;22(3):598-600.

45. Ayzenberg I, Lukas C, Trampe N, Gold R, Hellwig K. Value of MRI as a surrogate marker for PML in natalizumab long-term therapy. J Neurol. 2012;259(8):1732-1733.

46. Wipfler P, Harrer A, Pilz G, et al. Natalizumab saturation: biomarker for individual treatment holiday after natalizumab withdrawal? Acta Neurol Scand. 2014;129(3):e12-e15.

47. Lublin F, Miller DH, Freedman MS, et al. Oral fingolimod in primary progressive multiple sclerosis (INFORMS): a phase 3, randomised, double-blind, placebo-controlled trial. Lancet. Epub 2016 Jan 27.

48. Devonshire V, Havrdova E, Radue EW, et al. Relapse and disability outcomes in patients with multiple sclerosis treated with fingolimod: subgroup analyses of the double-blind, randomised, placebo-controlled FREEDOMS study. Lancet Neurol. 2012;11(5):420-428.

49. Al-Izki S, Pryce G, Jackson SJ, Giovannoni G, Baker D. Immunosuppression with FTY720 is insufficient to prevent secondary progressive neurodegeneration in experimental autoimmune encephalomyelitis. Mult Scler. 2011;17(8):939-948.

50. Karlsson G, Francis G, Koren G, et al. Pregnancy outcomes in the clinical development program of fingolimod in multiple sclerosis. Neurology. 2014;82(8):674-680.

51. Kleiter I, Gold R. Present and future therapies in neuromyelitis optica spectrum disorders. Neurotherapeutics. 2016;13(1):70-83.

52. Kompetenznentz Multiple Sklerose. Praktische Aspekte der Therapie mit Fingolimod, [July 2015]. Munich, Germany: Kompetenznetz Multiple Sklerose. Available from: http://www.kompetenznetz-multiplesklerose. de/images/stories/PDF_Dateien/kknms_handbuch_fty720_2015_frei. pdf. Accessed October 24, 2015. German.

53. Gold R, Comi G, Palace J, et al. Assessment of cardiac safety during fingolimod treatment initiation in a real-world relapsing multiple sclerosis population: a phase 3b, open-label study. J Neurol. 2014; 261(2):267-276.

54. Limmroth V, Haverkamp W, Dechend R, et al. Kardiale Ereignisse nach Erstgabe von Fingolimod: eine detaillierte Langzeit-EKG-Analyse. Poster presented at: 88 . Kongress der Deutschen Gesellschaft für Neurologie, September 23-26, 2015, Dusseldorf, Germany. German.

55. Warnke C, Dehmel T, Ramanujam R, et al. Initial lymphocyte count and low BMI may affect fingolimod-induced lymphopenia. Neurology. 2014;83(23):2153-2157.

56. Yamout BI, Zeineddine MM, Sawaya RA, Khoury SJ. Safety and efficacy of reduced fingolimod dosage treatment. J Neuroimmunol. 2015; 285:13-15.

57. Francis G, Kappos L, O'Connor P, et al. Temporal profile of lymphocyte counts and relationship with infections with fingolimod therapy. Mult Scler. 2014;20(4):471-480.

58. Abreu P, Peixoto C, Carvalho C, Santos L, Sarmento A, Sá MJ. A case of hemophagocytic lymphohistiocytosis syndrome in a patient with multiple sclerosis on fingolimod therapy. (P2.206). Neurology. 2014; 82(10 Suppl):P2.206-P2.206.

59. US Food and Drug Administration. FDA Drug safety communication, 08-04-2015. Silver Spring, MD: US Food and Drug Administration. Available from: http://www.fda.gov/downloads/Drugs/DrugSafety/ UCM457120.pdf. Accessed October 24, 2015.

60. Report on first case of progressive multifocal leucoencephalopathy under fingolimod. Available from: http://www.akdae.de/Arzneimittelsicherheit/ RHB/20150504.pdf. Accessed October 24, 2015.

61. Hoepner R, Ahlbrecht J, Faissner S, et al. Clinical and paraclinical findings in natalizumab-associated infratentorial progressive multifocal leukoencephalopathy patients. J Neurol Neurosurg Psychiatry. 2014; 85(10):1177-1178

62. Hoepner R, Faissner S, Klasing A, et al. Progressive multifocal leukoencephalopathy during fumarate monotherapy of psoriasis. Neurol Neuroimmunol Neuroinflamm. 2015;2(3):e85. 
63. Cohen JA, Khatri B, Barkhof F, et al. Long-term (up to 4.5 years) treatment with fingolimod in multiple sclerosis: results from the extension of the randomised TRANSFORMS study. J Neurol Neurosurg Psychiatry. 2015;2015:310597.

64. Montalban X, Comi G, Antel J, et al. Long-term results from a phase 2 extension study of fingolimod at high and approved dose in relapsing multiple sclerosis. J Neurol. 2015;262(12):2627-2634.

65. Johnson TA, Shames I, Keezer M, et al. Reconstitution of circulating lymphocyte counts in FTY720-treated MS patients. Clin Immunol. 2010;137(1):15-20.

66. Hakiki B, Portaccio E, Giannini M, Razzolini L, Pastò L, Amato MP. Withdrawal of fingolimod treatment for relapsing-remitting multiple sclerosis: report of six cases. Mult Scler. 2012;18(11):1636-1639.

67. Havla JB, Pellkofer HL, Meinl I, Gerdes LA, Hohlfeld R, Kümpfel T. Rebound of disease activity after withdrawal of fingolimod (FTY720) treatment. Arch Neurol. 2012;69(2):262-264.

68. Ghezzi A, Rocca MA, Baroncini D, et al. Disease reactivation after fingolimod discontinuation in two multiple sclerosis patients. J Neurol. 2013;260(1):327-329.

69. Sempere AP, Berenguer-Ruiz L, Feliu-Rey E. Rebound of disease activity during pregnancy after withdrawal of fingolimod. Eur J Neurol. 2013;20(8):e109-e110.

70. Alroughani R, Almulla A, Lamdhade S, Thussu A. Multiple sclerosis reactivation postfingolimod cessation: is it IRIS? BMJ Case Rep. 2014;2014

71. Berger B, Baumgartner A, Rauer S, et al. Severe disease reactivation in four patients with relapsing-remitting multiple sclerosis after fingolimod cessation. J Neuroimmunol. 2015;282:118-122.

72. De Masi R, Accoto S, Orlando S, et al. Dramatic recovery of steroidrefractory relapsed multiple sclerosis following fingolimod discontinuation using selective immune adsorption. BMC Neurol. 2015;15:125.

73. Mehling M, Johnson TA, Antel J, Kappos L, Bar-Or A. Clinical immunology of the sphingosine 1-phosphate receptor modulator fingolimod (FTY720) in multiple sclerosis. Neurology. 2011; 76(8 Suppl 3):S20-S27.

74. Cavone L, Felici R, Lapucci A, et al. Dysregulation of sphingosine 1 phosphate receptor-1 (S1P1) signaling and regulatory lymphocytedependent immunosuppression in a model of post-fingolimod MS rebound. Brain Behav Immun. 2015;50:78-86

75. Havla J, Kleiter I, Kümpfel T. Bridging, switching or drug holidays how to treat a patient who stops natalizumab? Ther Clin Risk Manag. 2013;9:361-369.

76. Sormani MP, Arnold DL, De Stefano N. Treatment effect on brain atrophy correlates with treatment effect on disability in multiple sclerosis Ann Neurol. 2014;75(1):43-49.

77. Radue EW, O'Connor P, Polman CH, et al. Impact of fingolimod therapy on magnetic resonance imaging outcomes in patients with multiple sclerosis. Arch Neurol. 2012;69(10):1259-1269.

78. Barkhof F, de Jong R, Sfikas N, et al. The influence of patient demographics, disease characteristics and treatment on brain volume loss in Trial Assessing Injectable Interferon vs FTY720 Oral in RelapsingRemitting Multiple Sclerosis (TRANSFORMS), a phase 3 study of fingolimod in multiple sclerosis. Mult Scler. 2014;20(13):1704-1713.

79. Sormani MP, De Stefano N, Francis G, et al. Fingolimod effect on brain volume loss independently contributes to its effect on disability. Mult Scler. 2015;21(7):916-924.

80. Foster CA, Howard LM, Schweitzer A, et al. Brain penetration of the oral immunomodulatory drug FTY720 and its phosphorylation in the central nervous system during experimental autoimmune encephalomyelitis: consequences for mode of action in multiple sclerosis. J Pharmacol Exp Ther. 2007;323(2):469-475.

81. Groves A, Kihara Y, Chun J. Fingolimod: direct CNS effects of sphingosine 1-phosphate $(\mathrm{S} 1 \mathrm{P})$ receptor modulation and implications in multiple sclerosis therapy. J Neurol Sci. 2013;328(1-2):9-18.

82. Harada J, Foley M, Moskowitz MA, Waeber C. Sphingosine-1phosphate induces proliferation and morphological changes of neural progenitor cells. J Neurochem. 2004;88(4):1026-1039.
83. Stessin AM, Gursel DB, Schwartz A, et al. FTY720, sphingosine 1-phosphate receptor modulator, selectively radioprotects hippocampal neural stem cells. Neurosci Lett. 2012;516(2):253-258.

84. Di Menna L, Molinaro G, Di Nuzzo L, et al. Fingolimod protects cultured cortical neurons against excitotoxic death. Pharmacol Res. 2013;67(1):1-9.

85. Cipriani R, Chara JC, Rodríguez-Antigüedad A, Matute C. FTY720 attenuates excitotoxicity and neuroinflammation. J Neuroinflammation. 2015;12:86

86. Deogracias R, Yazdani M, Dekkers MP, et al. Fingolimod, a sphingosine-1 phosphate receptor modulator, increases BDNF levels and improves symptoms of a mouse model of Rett syndrome. Proc Natl Acad Sci U S A. 2012;109(35):14230-14235.

87. Doi Y, Takeuchi H, Horiuchi H, et al. Fingolimod phosphate attenuates oligomeric amyloid $\beta$-induced neurotoxicity via increased brainderived neurotrophic factor expression in neurons. PLoS One. 2013; 8(4):e61988

88. Fukumoto K, Mizoguchi H, Takeuchi H, et al. Fingolimod increases brain-derived neurotrophic factor levels and ameliorates amyloid $\beta$-induced memory impairment. Behav Brain Res. 2014;268:88-93.

89. Coelho RP, Payne SG, Bittman R, Spiegel S, Sato-Bigbee C. The immunomodulator FTY720 has a direct cytoprotective effect in oligodendrocyte progenitors. J Pharmacol Exp Ther. 2007;323(2):626-635.

90. Miron VE, Jung CG, Kim HJ, Kennedy TE, Soliven B, Antel JP. FTY720 modulates human oligodendrocyte progenitor process extension and survival. Ann Neurol. 2008;63(1):61-71.

91. Miron VE, Ludwin SK, Darlington PJ, et al. Fingolimod (FTY720) enhances remyelination following demyelination of organotypic cerebellar slices. Am J Pathol. 2010;176(6):2682-2694.

92. Kim HJ, Miron VE, Dukala D, et al. Neurobiological effects of sphingosine 1-phosphate receptor modulation in the cuprizone model. FASEB J. 2011;25(5):1509-1518.

93. Hu Y, Lee X, Ji B, et al. Sphingosine 1-phosphate receptor modulator fingolimod (FTY720) does not promote remyelination in vivo. $\mathrm{Mol}$ Cell Neurosci. 2011;48(1):72-81.

94. Slowik A, Schmidt T, Beyer C, Amor S, Clarner T, Kipp M. The sphingosine 1-phosphate receptor agonist FTY720 is neuroprotective after cuprizone-induced CNS demyelination. Br J Pharmacol. 2015;172(1):80-92.

95. Oommen VV, Tauhid S, Healy BC, et al. The effect of fingolimod on conversion of acute gadolinium-enhancing lesions to chronic T1 hypointensities in multiple sclerosis. J Neuroimaging. Epub October 8, 2015.

96. Noda H, Takeuchi H, Mizuno T, Suzumura A. Fingolimod phosphate promotes the neuroprotective effects of microglia. J Neuroimmunol. 2013;256(1-2):13-18.

97. Van Doorn R, Van Horssen J, Verzij1 D, et al. Sphingosine 1-phosphate receptor 1 and 3 are upregulated in multiple sclerosis lesions. Glia. 2010;58(12):1465-1476.

98. Fischer I, Alliod C, Martinier N, Newcombe J, Brana C, Pouly S. Sphingosine kinase 1 and sphingosine 1-phosphate receptor 3 are functionally upregulated on astrocytes under pro-inflammatory conditions. PLoS One. 2011;6(8):e23905.

99. Colombo E, Di Dario M, Capitolo E, et al. Fingolimod may support neuroprotection via blockade of astrocyte nitric oxide. Ann Neurol. 2014;76(3):325-337.

100. Choi JW, Gardell SE, Herr DR, et al. FTY720 (fingolimod) efficacy in an animal model of multiple sclerosis requires astrocyte sphingosine 1-phosphate receptor 1 (S1P1) modulation. Proc Natl Acad Sci USA. 2011;108(2):751-756.

101. US National Institutes of Health. Available from: www.clinicaltrials gov. Accessed October 24, 2015.

102. Hacke W, Schwab S, Horn M, Spranger M, De Georgia M, von Kummer R. "Malignant" middle cerebral artery territory infarction: clinical course and prognostic signs. Arch Neurol. 1996;53(4):309-315.

103. Shichita T, Sugiyama Y, Ooboshi H, et al. Pivotal role of cerebral interleukin-17-producing gammadeltaT cells in the delayed phase of ischemic brain injury. Nat Med. 2009;15(8):946-950. 
104. Ahmad M, Graham SH. Inflammation after stroke: mechanisms and therapeutic approaches. Transl Stroke Res. 2010;1(2):74-84.

105. Gan Y, Liu Q, Wu W, et al. Ischemic neurons recruit natural killer cells that accelerate brain infarction. Proc Natl Acad Sci U S A. 2014; 111(7):2704-2709.

106. Macrez R, Ali C, Toutirais O, et al. Stroke and the immune system: from pathophysiology to new therapeutic strategies. Lancet Neurol. 2011; 10(5):471-480.

107. Iadecola $\mathrm{C}$, Anrather J. The immunology of stroke: from mechanisms to translation. Nat Med. 2011;17(7):796-808.

108. Chamorro Á, Meisel A, Planas AM, Urra X, van de Beek D, Veltkamp R. The immunology of acute stroke. Nat Rev Neurol. 2012; $8(7): 401-410$

109. Zhu Z, Fu Y, Tian D, et al. Combination of the immune modulator fingolimod with alteplase in acute ischemic stroke: a pilot trial. Circulation. 2015;132(12):1104-1112.

110. Neumann-Haefelin T, Kastrup A, de Crespigny A, et al. Serial MRI after transient focal cerebral ischemia in rats: dynamics of tissue injury, blood-brain barrier damage, and edema formation. Stroke. 2000;31(8):1965-1972; discussion 1972-1973.

111. Fu Y, Zhang N, Ren L, et al. Impact of an immune modulator fingolimod on acute ischemic stroke. Proc Natl Acad Sci U S A. 2014; 111(51):18315-18320.

112. Fu Y, Hao J, Zhang N, et al. Fingolimod for the treatment of intracerebral hemorrhage: a 2-arm proof-of-concept study. JAMA Neurol. 2014;71(9):1092-1101.

113. Campos F, Qin T, Castillo J, et al. Fingolimod reduces hemorrhagic transformation associated with delayed tissue plasminogen activator treatment in a mouse thromboembolic model. Stroke. 2013; 44(2):505-511.

114. Lukiw WJ, Bazan NG. Survival signalling in Alzheimer's disease. Biochem Soc Trans. 2006;34(Pt 6):1277-1282.

115. Mielke MM, Haughey NJ, Bandaru VV, et al. Cerebrospinal fluid sphingolipids, $\beta$-amyloid, and tau in adults at risk for Alzheimer's disease. Neurobiol Aging. 2014;35(11):2486-2494.

116. Han X, Holtzman DM, McKeel DW, Kelley J, Morris JC. Substantial sulfatide deficiency and ceramide elevation in very early Alzheimer's disease: potential role in disease pathogenesis. J Neurochem. 2002; 82(4):809-818.
117. Cutler RG, Kelly J, Storie K, et al. Involvement of oxidative stressinduced abnormalities in ceramide and cholesterol metabolism in brain aging and Alzheimer's disease. Proc Natl Acad Sci US A. 2004; 101(7):2070-2075.

118. He X, Huang Y, Li B, Gong CX, Schuchman EH. Deregulation of sphingolipid metabolism in Alzheimer's disease. Neurobiol Aging. 2010;31(3):398-408.

119. Grimm MO, Rothhaar TL, Hartmann T. The role of APP proteolytic processing in lipid metabolism. Exp Brain Res. 2012;217(3-4): $365-375$.

120. Kaneider NC, Lindner J, Feistritzer C, et al. The immune modulator FTY720 targets sphingosine-kinase-dependent migration of human monocytes in response to amyloid $\beta$-protein and its precursor. FASEB J. 2004;18(11):1309-1311.

121. Takasugi N, Sasaki T, Ebinuma I, et al. FTY720/fingolimod, a sphingosine analogue, reduces amyloid- $\beta$ production in neurons. PLoS One. 2013;8(5):e64050.

122. Asle-Rousta M, Kolahdooz Z, Oryan S, Ahmadiani A, Dargahi L. FTY720 (fingolimod) attenuates $\beta$-amyloid peptide (A $\beta 42)$-induced impairment of spatial learning and memory in rats. J Mol Neurosci. 2013;50(3):524-532.

123. Di Pardo A, Amico E, Favellato M, et al. FTY720 (fingolimod) is a neuroprotective and disease-modifying agent in cellular and mouse models of Huntington disease. Hum Mol Genet. 2014;23(9):2251-2265.

124. Miguez A, García-Díaz Barriga G, Brito V, et al. Fingolimod (FTY720) enhances hippocampal synaptic plasticity and memory in Huntington's disease by preventing p75NTR up-regulation and astrocyte-mediated inflammation. Hum Mol Genet. 2015;24(17):4958-4970.

125. Zhang Z, Zhang ZY, Fauser U, Schluesener HJ. FTY720 ameliorates experimental autoimmune neuritis by inhibition of lymphocyte and monocyte infiltration into peripheral nerves. Exp Neurol. 2008;210(2):681-690.

126. Zhang ZY, Zhang Z, Schluesener HJ. FTY720 attenuates lesional interleukin-17(+) cell accumulation in rat experimental autoimmune neuritis. Neuropathol Appl Neurobiol. 2009;35(5):487-495.

127. Gonzalez-Cabrera PJ, Brown S, Studer SM, Rosen H. S1P signaling: new therapies and opportunities. F1000Prime Rep. 2014;6:109.

128. Subei AM, Cohen JA. Sphingosine 1-phosphate receptor modulators in multiple sclerosis. CNS Drugs. 2015;29(7):565-575.
Therapeutics and Clinical Risk Management

\section{Publish your work in this journal}

Therapeutics and Clinical Risk Management is an international, peerreviewed journal of clinical therapeutics and risk management, focusing on concise rapid reporting of clinical studies in all therapeutic areas, outcomes, safety, and programs for the effective, safe, and sustained use of medicines. This journal is indexed on PubMed Central, CAS,
Dovepress

EMBase, Scopus and the Elsevier Bibliographic databases. The manuscript management system is completely online and includes a very quick and fair peer-review system, which is all easy to use. Visit http://www.dovepress.com/testimonials.php to read real quotes from published authors. 